\title{
Predicate Decomposition, and Linking Syntax and Semantics: A Brazilian Portuguese Analysis*
}

\author{
Márcia Cançado and Luisa Godoy (Brazil)
}

\begin{abstract}
This paper presents a theoretical proposal on the lexical-syntax relationship, related to verbs. In essence, the proposal consists of two tasks: a) to corroborate the idea of lexically representing verbs by means of a semantic predicate decomposition and, more importantly, $b$ ) to propose a linking mechanism between such lexical-semantic level and syntax itself. The contribution of this study consists in the form and manner in which the linking occurs. Even though linking theories abound in the literature, and even though in a general sense the approach presented here is not new, there are some relevant details that distinguish it from previous proposals, as it will become clear. Furthermore, from an empirical point of view, there is originality in the description we make of a vast group of verbs from Brazilian Portuguese (BP) that serves as a demonstration of the theoretical proposal.
\end{abstract}

\section{$1 \quad$ Introduction}

This article presents a theoretical proposal on the lexical-syntax relationship, related to verbs. In essence, the proposal consists of two tasks: a) to corroborate the idea of lexically representing verbs by means of a semantic predicate decomposition and, more importantly, $b$ ) to propose a linking mechanism between such lexical-semantic level and syntax itself. The contribution of this study consists in the form and manner in which the linking occurs. Even though linking theories abound in the literature, and even though in a general sense the approach presented here is not new, there are some relevant details that distinguish it from previous proposals, as it will become clear. Furthermore, from an empirical point of view, there is originality in the description we make of a vast group of verbs from Brazilian Portuguese (BP) that serves as a demonstration of the theoretical proposal. The text is divided in the following manner: in section 1 , we justify the hypothesis of the argument structure having a semantic content and motivate the need of a linking between this structure and syntax; in section 2, we expose our proposal, describing the shape that the representation of the argument structure and the linking will assume, justifying these choices and describing, in detail, the mechanism of such mapping; in section 3, we present an exemplification of the proposal by means of an analysis of BP verbs; in section 4, we provide a synthesis of the presented proposal, pointing out gaps and possibilities for futures studies.

\footnotetext{
*The authors thank the financial support from CNPq and FAPEMIG.
} 


\section{$2 \quad$ Semantics in argument structure?}

From the stand point that argument structure is the part of the lexical entry which is relevant for grammar (Grimshaw 1990), we ask: Is there semantic information in argument structure? In other words: Is there semantic information that is grammatically relevant?

Recent literature depicts several arguments in favor of an argument structure exempt of semantic information (Hale/Keyser 1993, 2002; Borer 2005; Ramchand 2008; Marantz 1997; Harley 2007; Pylkkanen 2008; among others). Furthermore, in formal studies, nowadays, the idea is almost consensual that the external argument is not syntactically introduced by the verbal head (since Kratzer 1996, who expanded Marantz's 1984 intuition), but by a functional head above VP. The two ideas taken together appear in the literature as argument structures like the following one, extracted from Hale and Keyser (2002):

(1) Verb clear:

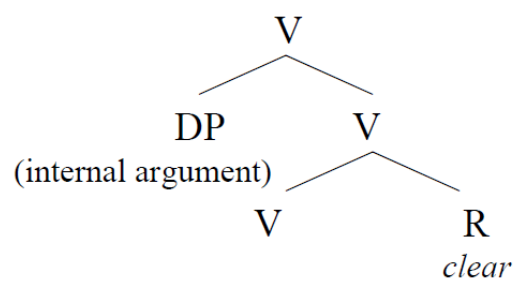

In this argument structure, there is only room for the internal argument, while the external argument is directly introduced in sentential syntax. The complement position of $\mathrm{V}$ is occupied by a root $(\mathrm{R})$, which merges, in a process the authors call conflation, with the light verbal head (V), conferring phonological content to it. It is obvious that the authors assume some semantics in lexical information; however, it is something idiosyncratic or encyclopedic ${ }^{1}$, and confined to the root.

The problem with a purely syntactic argument structure is the existence of semantic information to which syntax appears to be sensitive. This was, as a matter of fact, admitted by Hale and Keyser (2002) themselves, who propose what they call "manner features", semantic in essence, in order to explain the asymmetry of verbs such as splash and such as smear in respect to the transitive-intransitive alternation in English (John splashes mud on the wall/Mud splashes on the wall, but John smears mud on the wall/*Mud smears on the wall). In other words, even though they propose syntactic argument structures for both types of verbs, they must acknowledge that lexical semantics is responsible for why verbs that are apparently identical in their lexical structures do not behave in the same way in sentential syntax. Thus, even without saying it, the authors are admitting that semantic information determine a certain grammatical behavior, which is incongruent with their own theoretical proposal, in which semantics only interpret syntax, that is, "reads" the configuration of arguments and attributes meaning to them.

It is precisely this incongruence that Mateu (2010) aims to repair. He proposes abandoning the "manner features", rethinking them as verbal roots that undergo a different type of

\footnotetext{
${ }^{1}$ In the case of Marantz (1997), Harley (2007) e Ramchand (2008), for whom the theoretical trend is Distributed Morphology, idiosyncratic semantics is not lexical (it is a non-lexicalist theory), but belonging to a posterior level to syntactic derivation, the "Encyclopedia", where idiosyncratic senses are listed.
} 
incorporation with the abstract verb (instead of the incorporation ${ }^{2}$ with a root in an argument position, he proposes the incorporation with the root in adjunction). In the derivation of each type of verb, incorporation occurs in a different place within the lexical-syntactic structure, generating a different configuration, which explains the possibility of the transitiveintransitive alternation with splash and its impossibility with smear. Thus, as stated by the author, the interpretations that Hale and Keyser (2002) called "agent-manner" (for verbs such as smear) and "patient-manner" (for verbs such as splash) derive from the different configurations, not the other way around.

Even though Mateu's proposal repaired the specific problem of manner features in verbs such as splash and smear, it seems that there are still other cases in which lexical-semantic information seems to be grammatically relevant, yet non-representable in a pure syntactic argument structure (such as in (1)). Here are two of them, taking BP as example.

Passivization seems to be sensitive to the presence of an agentive external argument, as it has already been pointed out in an earlier work from Jackendoff (1972) (although it does not mean that there is an agent in every passive). Cançado and Franchi (1999) show that there is a subclass of psychological object-experiencer verbs in BP that do not attribute agentivity to their external argument, not even when it is animated ${ }^{3}$ :
a. * A filha the daughter
preocupou a the
mãe
com uma
faca.
b. * Pedro
aborreceu o pai mother with a knife Pedro displeased the father with um martelo.
c. * Maria chateou o namorado com um revólver. Maria annoyed/upseted the boyfriend with a handgun

But:
a. Pedro assustou Maria com um revólver. Pedro frightened Maria with a handgun
b. Pedro acalmou Maria com um chá. Pedro calmed Maria with a tea
c. Os colonizadores apaziguaram os índios com presentes. the colonists appeased the natives with gifts

The instrument can only be licensed in the presence of a real agent (Cançado/Franchi 1999), therefore, the psychological verbs in (3) accept being composed with an instrument, but not the psychological verbs in (2). Note that the verbs which do not accept an agent, do not accept passivization either, but those which accept an agent, accept being passivized:
a. * A mãe the mother was worried
pela filha. by the doughter

\footnotetext{
2 In fact, the incorporation in the proposal by Hale and Keyser (2002) is conflation, as mentioned above, in the brief explanation for (1). The concept is revisited on footnote 8 .

${ }^{3}$ Generally, it is assumed in literature that most verbs belonging to the class of psychological verbs with an experiencer object are ambiguous between an agentive interpretation and a non-agentive interpretation (Landau 2010; Grimshaw 1990). However, in BP, according to a survey performed by Cançado and Franchi (1999), there is a group of verbs (130 in 210 object-experiencer psychological verbs) that do not accept the agentive interpretation in any context.
} 

b. * $\mathrm{O}$ pai foi aborrecido por Pedro. the father was displeased by Pedro
c. * $\mathrm{O}$ namorado foi chateado por Maria the boyfriend was annoyed by Maria

(5) a. Maria foi assustada por Pedro.

Maria was frightened by Pedro

b. Maria foi acalmada por Pedro.

Maria was calmed by Pedro

c. Os índios foram apaziguados pelos colonizadores.
the natives were appeased by the colonists

In short, the possibility or impossibility of an agent occupying the external argument position is what subdivides BP object-experiencer psychological verbs in two classes, that of verbs in (2) and that of verbs in (3). This is a piece of semantic information which is grammatically relevant because passivization (a grammatical operation) is sensitive to it. However, there is no place for this information in a purely syntactic argument structure, such as in (1): neither semantic information fits in it, nor the external argument is represented.

A second example of lexical-semantic information relevant in BP grammar occurs with the classes of location verbs (such as shelf, bottle and hospitalize) and locatum ${ }^{4}$ verbs (such as spice, ciment and handcuff), revisiting the famous nomenclature by Clark and Clark (1979). Hale and Keyser (2002) represent both types of verbs with the same lexical-syntactic structure:

(6)

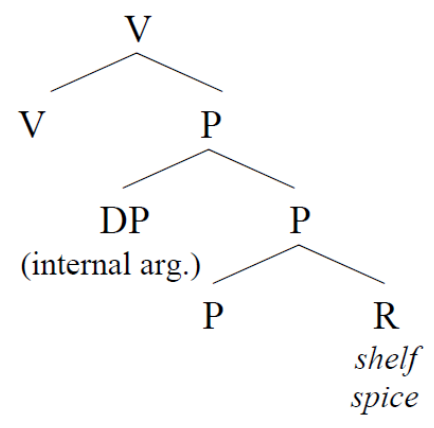

Both location and locatum verbs are formed by the incorporation process (or conflation) of a root-noun with an abstract preposition and successively with the light verb (in BP, besides the light verb, there can be a verb-forming morpheme, such as en- or $a$ - in V position). Once again, the external argument is "severed" and only the internal argument has its place within the argument structure, in Spec of $\mathrm{P}$.

In BP, both classes can be reflexivized:
a. Pedro Pedro
hospitalizou
Maria. hospitalized Maria
b. Pedro se hospitalizou.
Pedro -reflexive clitic se- hospitalized

\footnotetext{
4 These verbs, although they were firstly analyzed for English, find perfect translations in Portuguese.
} 
Márcia Cançado and Luisa Godoy: Predicate Decomposition, and Linking Syntax and Semantics: 47

A Brazilian Portuguese Analysis

$$
\begin{array}{clc}
\text { Pedro } & \text { algemou } & \text { Maria. } \\
\text { Pedro } & \text { handcuffed } & \text { Maria } \\
\text { Pedro } & \text { se } & \text { algemou }^{5} \text {. } \\
\text { Pedro } & \text {-reflexive clitic } s e \text {-handcuffed }
\end{array}
$$

Godoy (2012) argues, however, that the two types of reflexive sentences differ in certain aspects. Reflexive sentences with locatum verbs, such as (9), seem to be a case of "strictu sensu" reflexive, since they are well paraphrased in BP with the anaphoric expression si mesmo ('himself'), as shown in (10) below:

(10) Pedro hospitalizou a si mesmo.
Pedro hospitalized to himself

Godoy (2012) proposes that the element which impinges this "middle"6 interpretation in the reflexivization of location verbs is the presence of a locative argument, even when it is abstract, or implicit. It seems that whenever there is a location in the argument structure of the verb, there will be a "middle" reading if the verb is reflexivized. That is, the different result in the reflexivization of location and locatum verbs is due to the fact that the abstract prepositions in each class has a distinct semantic value - one establishes a location relationship between two arguments, one of which is implicit, while the other establishes a relationship of possession between two arguments, one of which is implicit (Hale/Keyser 2002).

In short, even though location and locatum verbs have the same argument configuration, in which there is an abstract preposition (taking Hale and Keyser's proposal), we see that the semantic content of this preposition seems to be relevant for the formation of either a strictu sensu or a middle reflexive sentence. Again, we have a case of lexical-semantic information to which grammar seems to be sensitive, but that do not find room in a purely syntactic argument structure representation, such as the structure in (6), that does not represent the semantic value of the preposition.

In fact, subjacent to Hale and Keyser (2002)'s argumentation for the postulation of the structure in (6), common to location and locatum verbs, there seems to be a semantic motivation. The authors' analysis seems to take the paraphrases of the verbs (put $Y$ in $R$, for verbs of location and provide $Y$ with $R$, for verbs of locatum) as its starting point ${ }^{7}$. Furthermore, the authors themselves refer to the different senses of abstract prepositions in verbs of location (locative sense, such as in) and locatum (possessive sense, such as with). Again, if abstract prepositions are to assume semantic values, it would be a contradiction, such as the one pointed out in Mateu (2010), because semantics should read a syntactic configuration and confer sense to it due to the positioning of arguments. In other words, abstract prepositions of location and locatum verbs should receive the same general

\footnotetext{
5 Only verbs which accept animated internal arguments can be reflexivized (Godoy 2012). That is why we showed examples of reflexives with verbs like hospitalize and handcuff and not verbs that allow only an inanimate internal argument, such as shelf and ciment.

${ }^{6}$ Godoy (2012) argues that the middle reading in some reflexive sentences in BP means that cause is absent in the interpretation of those sentences. Since it is not our purpose here to deal with the complex semantic process of reflexivization in BP, we will not develop the whole argumentation for the decausativization in reflexive middles, which can be found in the work cited above.
} 
interpretation, because their configurations are identical. By admitting different values for abstract prepositions in the lexical structure, Hale and Keyser (2002) are, in fact, corroborating a proposal such as the one we are going to propose here.

In sum, there is a need to allocate semantic information in the verb's argument structure, if argument structures are understood to be the place in the lexicon where grammatically relevant information is contained. If we return to an earlier conception of semantic argument structure, be it with thematic roles (such as in Gruber 1965; Halliday 1967; Fillmore 1968, 1971; Chafe 1970; Jackendoff 1972; among others), be it in structures of decomposed events or predicates (such as in Jackendoff 1990; Van Valin/LaPolla 1997; Van Valin 2005; Croft 1998; Levin/Rappaport 1995, 1998, 2005, 2010; among others), we obtain the satisfaction of such need. But, what do we lose?

According to Pylkkanen (2008), syntactic theories of lexical representation are ways of escaping the linking problem. Authors which propose semantic lexical representations must acknowledge that an additional apparatus in needed - a mapping mechanism for semantic arguments into syntactic positions. The author revisits, as an example, the two linking rules proposed by Levin and Rappaport-Hovav (1995: 136):

(11) a. "Immediate cause linking rule": the verbal argument which denotes the immediate caused for the eventuality described by that verb is its external argument.

b. "Directed change linking rule": the verbal argument which corresponds to the entity that suffers a directed change described by the verb is its direct internal argument."

For Pylkkanen, the problem with proposals such as that of Levin and Rappaport-Hovav is that is seems to be more "generalizations about observed correspondences between argument positions and its interpretations" (ibd.: 4) than independently motivated theories about how language projects its lexical items in syntax.

The purpose of this article is precisely that of proposing a linking theory that is more formalized and economic. The argument structures shall be semantic and an additional linking mechanism will be needed, however, it will arise from the intuitions and contributions that are being brought about by the syntactic theories of lexical representation. That is, the lexicalsyntactic structures shall be used, not as representations of argument structure, but as linking between lexicon and syntax.

In this section, we argued for the need of a semantic representation of argument structure and demonstrated the consequent need for a linking mechanism. In the next section, we show the shape which such representation and the linking take in the proposal sketched here. It is worth observing that although we borrow the main elements of this proposal from previous work in recent linguistic literature, the way we connect these elements in the lexical semantics-syntax interface, explaining the BP data to be presented, is different. Let us now take a look on how this proposal is articulated.

${ }^{7}$ As it is also been pointed out by Levin and Rappaport-Hovav (2005). 


\section{The syntax-lexical semantics interface}

\subsection{Argument structure}

In our proposal, the semantic argument structure will take the shape of a predicate decomposition structure, following Dowty (1979), Jackendoff (1990), Van Valin and LaPolla (1997), Van Valin (2005), Croft (1998) and, more closely, Wunderlich (1997, 2012), Levin and Rappaport-Hovav (1995, 1998, 2005, 2010) and Levin (1999, 2009).

Wunderlich (2012) shows that one of the strongest arguments for lexical decomposition comes from verbs called denominal. For example, in English, nouns such as bag, cage, butter and salt refer to places or substances. However, there are verbs related to these nouns, which refer to events. For example:

(12) a. Jane boxed the cooks.

b. Jane caged the lion.

(13) a. Jane buttered the bread.

b. Jane salted the food.

The verbs in (12) and (13) are respectively location and locatum verbs, to which we referred earlier. Certainly, they contain the concepts of box/cage and butter/salt as one of their components. Along with that concept, which is called "root", there are other semantic units that compose the eventual meaning of the verbs. It is possible to formulate paraphrases that highlight the relationship between these nouns and the other semantic units in the semantic formation of the verbs above:

(14) a. Jane put the cooks in the box.

b. Jane put the lion in the cage.

(15) a. Jane put butter on the bread.

b. Jane put salt in the food.

By means of the paraphrases, we notice that there are recurrent meaning components in each verb group.

Perhaps the argument most traditionally used (since Morgan 1969 and the generative semanticists, brushing on Dowty 1979 and heavily explored by Von Stechow 1995) to show that the meaning of the verbs can be decomposed in smaller semantic units is that of the ambiguity of scope in the composition of an adverb (such as almost) with certain verbs:

(16) a. Pedro almost persuaded Maria to dance.

b. What Pedro almost did was persuade Maria to dance.

c. What Pedro did was almost persuade Maria to dance.

In (b) and (c) we see paraphrases of each of the ambiguous meanings of (a). The examples show that the adverb almost can have scope over different internal parts in the meaning of the verb persuade.

Denominal verbs and the ambiguity in the scope of adverbs are examples of a few of the evidences used to argue for an analysis in which the semantics of verbs is not unitary, but 
composed of subparts or components ${ }^{8}$. It was the generative semanticists (Lakoff 1970; Ross 1969; McCawley 1968) who first proposed to represent such components in a metalanguage, inspired in formal logic, of predicates and arguments. The way in which this type of semantic decomposition fit in the structure of the grammar proposed by the generative semanticists was later heavily criticized, nevertheless, the idea of decomposing the meaning of the items, and of representing this decomposition by means of primitive predicates, has perpetuated in linguistic studies since then. Let us take a look at the structure proposed by Levin and Rappaport-Hovav (2005) for a change of state verb, break:

\section{(17) break: [[X ACT] CAUSE [Y BECOME <BROKEN>]]}

The decompositions are always composed by metapredicates, such as ACT and BECOME and by their arguments, which may be variables, such as $\mathrm{X}$ and $\mathrm{Y}$, or roots, such as $<B R O K E N>$ (we shall consider roots below). The external brackets delimitate the whole event named by the verb and the internal structures between brackets represent subevents. In the structure above, there are two subevents, related to each other by means of the metapredicate CAUSE. CAUSE, in its turn, is not a predicate that takes individuals to be saturated, such as ACT or BECOME, but a predicate that takes subevents as arguments.

Nowadays, it is a consensus in decompositional proposals (even in the syntactic and in the constructional theories) the opposition between root and structure (Ramchand 2008; Goldberg 1995; Hale/Keyser 2002; Marantz 1997; Pesetsky 1995; Pinker 1989; Levin/RappaportHovav, 1998, 2005, 2010; Levin 1999; Grimshaw 2005; Mateu 2010, among others). The structure is everything but the root in a decomposition; it represents the part of the verbal meaning that the verb shares with the other members of the verbal class to which it belongs. The root is the unitary, idiosyncratic part of verbal meaning, which belongs to a single specific verb, and is represented between angled brackets $(<>)$. As per Levin and RappaportHovav (2005), the roots, even though idiosyncratic, may be classified according to their ontological categories. Among the ontological categories most frequent in literature are STATE, RESULT, THING, PLACE, MANNER and INSTRUMENT. While THING and PLACE are argument roots, MANNER and INSTRUMENT are predicate modifiers (Levin/Rappaport-Hovav 2010) and STATE is a predicate (Wunderlich 2012).

It was briefly shown above which elements compose an argument structure representation in semantic predicate decomposition terms. There will be more examples of these structures in the proposal exemplification, in the following section. Before it, let us highlight why a representation of argument structure in terms of predicate decomposition seems to be preferable over a representation in terms of thematic grids.

Firstly, a semantic predicate decomposition represents not only the semantics of the participants in the event (such as in the representations by thematic grids), but also, and mainly, the semantics of the event itself. For example, among the great group of verbs that we shall call verbs of change, there are change of state verbs, such as clear, change of possession verbs, such as butter, and change of location verbs, such as hospitalize. In a description in terms of thematic roles, all three types would have the same representation - a thematic grid

\footnotetext{
${ }^{8}$ Against the work of Jerry A. Fodor, the main critic of lexical decomposition since the 1970's (his first explicit critic appears to have been Fodor 1970).
} 
with two arguments, an agent and a patient. However, in a description in terms of predicate decomposition, the representations of the three types of verb differ, as shown below:

(18) clear: [[X (ACT)] CAUSE [BECOME Y <CLEAR>]]

(19) butter: [[X ACT] CAUSE [BECOME Y WITH $<B U T T E R>]]$

(20) hospitalize: [[X ACT] CAUSE [BECOME Y IN $\langle H O S P I T A L\rangle]]$

These representations clearly show which part of the verbal meaning is shared by the three classes: all three have two subevents, which have as their nucleus ACT and BECOME, related by CAUSE. The structures also highlight which part of the meaning is shared by verbs of the same class. Verbs of the type in (18) have in common the ontological category STATE (represented by the root clear, in the example). Verbs of the type in (19) have in common the predicate WITH. Verbs of the type in (20) have in common the predicate IN. Moreover, the predicates WITH and IN are a part of the argument of BECOME. Finally, the structures also represent the part of the meaning which is idiosyncratic for each particular verb (the root in each structure above - CLEAR, BUTTER and HOSPITAL). Furthermore, they highlight the number of subevents in the semantics of the verb (two subevents in the examples above) and the type of "conjunction" (Wunderlich 1997) between them (in the examples, CAUSE). Using decomposition, the semantic function of the participants of the event (or their thematic role) can derive from the position the arguments occupy in predicate decomposition structures (what relation the arguments bear with the predicate they saturate), so they do not need to be defined aprioristically (Jackendoff 1990). To give an example, what is traditionally called "agent" can be defined as the argument that saturates ACT.

When one observes the semantics of the event and of its subparts, rather than only the semantics of the participants, relevant analytic consequences arise. As argued by Parsons (1990), among others, in an analysis of the causative-inchoative alternation (João broke the vase $>$ the vase broke) in terms of thematic roles solely, the difference between the two forms consists only in the presence of an extra argument in the causative form. However, the author shows this analysis would not be able to explain that in the causative form there are two subevents, while in the inchoative there is only one. Neither would it be able to explain that the causative form, as its name indicates, contains CAUSE (relating the two subevents), while the inchoative form does not (because it contains only one subevent). See bellow the representation of that alternation in terms of predicate decomposition, adapted from Cançado and Amaral (2010):

(21) a. causative form: [[X (ACT)] CAUSE [BECOME Y <STATE>]] (such as in João broke the vase.)

b. inchoative form: [BECOME Y <STATE $>$ ] (such as in The vase broke.)

In a predicate decomposition representation such as this, it is clear that there is an extra subevent in the causative form, which explains, for instance, the aspectual contrast between the two forms (the causative form is an accomplishment and the inchoative form is an achievement, according to Dowty 1979's classical definitions of the aktionsarts). Furthermore, as argued by Levin and Rappaport-Hovav (2005), in a representation in terms of thematic roles, it is impossible to make a distinction between root and structure, which is a considerable disadvantage for analytical resources, since there are grammatical properties which are sensitive to that distinction (see, on this subject, Grimshaw 2005). 
In this subsection, we have shown in what way a lexical verbal meaning has subparts (or can be decomposed). Also, we pointed out the elements which compose an argument structure representation in terms of semantic predicate decomposition. And we showed some motivation for choosing this formal representation instead of another (thematic grids). Let us now expose the form and the manner in which the linking between that semantic structure and syntax will take in the proposal sketched here.

\subsection{Linking}

In elaborating our linking, we make use of syntactic theories of argument structure, which are, according to Levin and Rappaport-Hovav (2005, p. 69), syntactic versions of predicate decomposition. Among current proposals, we select that of Hale and Keyser (2002), hereinafter HK, which intends to be sufficiently wide to account for every type of argument configuration. Regarding verbs, the authors propose the following types of argument structure:

(22)

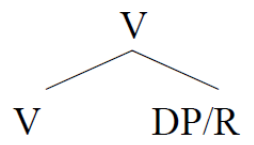

(23)

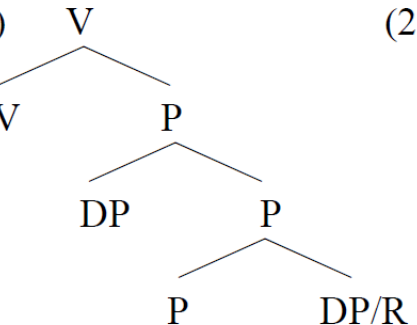

(24)

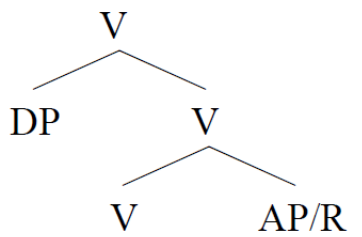

The structures in (22) and (23) are monadic verbs, which project only one relational position that of a complement. The difference between the two structures is that, in (22), the V takes a nominal complement and, in (23), a prepositional complement. The noun is a saturated category, while the preposition is an unsaturated category, therefore it opens a projection, which is dyadic (in HK proposal, P takes on not one, but two arguments to get saturated). In reality, (22) and (23) are instances of the same type of verbal argument structure, where V takes a complement and does not project Spec. On the other hand, (24) is a dyadic verbal structure, where V takes a complement and opens the Spec position. For HK, it is the element in complement position (an adjective or a root with adjectival value) that forces Spec to be projected. Due to this "parasitism" in which the V projects Spec in order to satisfy the need of the complement for an argument position, the authors call the structure "composite dyadic".

The presence of an internal argument in Spec, $\mathrm{V}$ is what determines the verb's possibility to alternate between an intransitive-inchoative form and a transitive-causative one. In sentential syntax, the internal argument of verbs whose lexical-syntactic structure is (24) can either be raised to subject position, forming an intransitive sentence, or occupy the object position, in the presence of an external argument. On the other hand, in the lexical-syntactic structure of verbs which do not project Spec, such as (22) and (23), there is no argument that can be alternated.

Verbs are originally monadic (except when they enter into a relationship of parasitism with an adjectival complement, thus becoming dyadic), and the only category essentially bi-relational is the preposition. The positions of complement of $\mathrm{V}$ and complement of $\mathrm{P}$ can be filled with either a noun phrase (DP in (22) and (23) and AP in (24)) or a root. In the case where noun 
phrases fill these positions, the categories are explicit ("overt"), not abstract ("covert") and the verbs are analytical. For example, (22) is the structure of an analytical verb such as make (as in make a fuss); (23) is the structure of an analytical verb such as put (as in put the book on the table); and (24) is the structure of an analytical verb such as turn (as in turn the leaves red).

However, when $\mathrm{R}$ fills the position of complement of $\mathrm{V}$ or of $\mathrm{P}$, that is when there are implicit or abstract heads and the merging of the abstract head with its complement assumes the form of a process that HK call conflation ${ }^{9}$. This is the formation of synthetic verbs, which are named after an internal component in its decomposition. For example, a root such as laugh conflates with an abstract $\mathrm{V}$ in a structure such as (22), deriving the verb laugh. This is HK's classical analysis for unergative verbs. However, a structure such as (23), for instance, derives a verb such as bag (as in bag the potatoes), in the process of conflation of the root-noun bag in a position of complement of $\mathrm{P}$ with the abstract preposition and successively with the abstract verb. This is the formation of a location verb, identical to the formation of a locatum verb, such as butter (as in butter the bread), where conflation happens between the root-noun butter with the head $\mathrm{P}$ and successively with the abstract verbal head ${ }^{10}$.

It is worth mentioning that HK's analysis for locatum verbs therefore differs from Clark and Clark (1979)'s, who first identified this verbal class. HK suggest a different paraphrase for these verbs; for the verb butter, for example, the paraphrase would be provide $Y$ with butter and not put butter in/on $Y$, as originally proposed by Clark and Clark. The reason for this is that locatum verbs, in order to be formed by conflation (because they are synthetic), must have a configuration such as (23), where $\mathrm{R}$ is complement, and not Spec of $\mathrm{P}$. The authors argue that if we admit the existence of the process of conflation of names in the position of Spec, P with a V, we would derive impossible verbs such as the ones below:

*John booked in the drawer.

*John buttered in the bread.

In summary, synthetic verbs of location and locatum derive from the process of conflation of a root-noun with an abstract preposition and successively with an abstract verb. The difference between the two classes lies solely in the meaning of the preposition. In location verbs, the abstract preposition means place: to put $y$ in; and in locatum verbs, the preposition means possession: to provide $y$ with ${ }^{11}$.

Finally, a structure such as (24) derives a synthetic verb in the following manner: an adjectival root such as clear conflates with the abstract verb deriving the verb clear (such as in clear the sky). This is a synthetic verb also known as deadjectival, while unergative verbs (such as laugh), location verbs (such as bag) and locatum verbs (such as butter) are often

\footnotetext{
9 "Conflation" is a reformulation of the earlier study by Hale and Keyser (1993), which uses the idea of "incorporation" from Baker (1988). Generally speaking, conflation occurs concomitantly to merge in order to satisfy the requirement of phonologic content of an abstract head. Put simply, it is the operation needed to show that $\mathrm{V}$ (and also $\mathrm{P}$, in some occasions) takes on the name of its complement.

${ }^{10}$ In the authors' proposal, the same structure in (23) also derives, from nominal roots, psychological verbs such as love and anger and result verbs such as cut.

11 This is an incongruity in HK's proposal, as observed before. If location and locatum verbs have the same lexical-syntactic configuration and the semantics is purely interpretive, the interpretation of their abstract preposition should be the same.
} 
times referred to as denominal. In their work, HK sometimes identify the category of the root that undergoes conflation (A or N), and sometimes they simply name it R. Here, we are using only $\mathrm{R}$, because, even though it is assumed that there is an implicit argument in synthetic verbs, which indeed relates to a name or an adjective that already exists in the language, it is not assumed that every synthetic verb with a configuration such as (22) or (23) derives from an noun, or that every synthetic verb with a structure such as (24) derives from an adjective. The authors themselves admit that a verb such as break, for instance, cannot be a priori classified as deadjectival. Let it be noted that the non-categorization of roots is in consonance with recent syntactic proposals of predicate decomposition, where roots do not bare a category (such as Harley 2007; Marantz 1997), however, we shall not extend this issue any longer.

Above we reported HK's proposal for the argument structure of verbs. In our proposal, we will assume HK,'s configurations as they are, however, we will consider them a linking between semantic argument structures (represented by the predicate decomposition) and sentential syntax. Obviously, we must abandon the idea that semantics only interprets argument structure, that is, the idea according to which all that is known about the meaning of verbal arguments is derived from interpreting its position in a lexical-syntactic structure (Hale/Keyser 1993).

It is also worth pointing out the differences our proposal bares in relation to the early "Generative Semantics" program. The semantic elements from predicate decomposition structures will never be present in a syntactic structure; neither will they be moved around in the course of transformations. These elements belong to a semantic level of lexical information and find a natural parallel (a "mirroring") in a syntactic level, in which arguments and predicates are allocated in hierarchical configurations exempt of meaning; however, it is a level that is previous to syntax per se, which is sentential syntax. What we are doing is making explicit, within a theoretical proposal, relationships that have long been pointed out in literature - for instance, the relationship between $v^{0}$ (the "little $\left.v^{\prime \prime}\right)$ and the semantic notion of cause.

In summary, even though we make use of HK's structures for representing hierarchical relationships between arguments and metapredicates (absorbing the intuition that there is in fact some syntax in the lexicon), we will not assume the theoretical basis that is connected with this representation. The structures for us represent the linking between argument structure and sentential syntax and not the argument structure itself. As briefly discussed above, this changes the place into which semantics will fit within the theory - not only as an interpretative component, but as a grammatically relevant part of lexical information.

One last point in the theoretical distinction in relation to HK's proposal is whether the structures exist or not in syntax itself. According to HK, "the representations (...) do not exist at any stage in the syntactic representation of sentences" (Hale/Keyser 1993: 17), and that is due to the fact that the structures are argument structures and, therefore, belong to the lexicon. However, if we consider them as linking, we can think of the structures as the "lexical phase" in the derivation, that is, as structures that actually exist in sentential syntax (cf. Ramchand 2008). This is the sense in which our proposal intends to be more economic than other linking proposals, because it is not necessary to postulate a mechanism of a different nature (neither 
lexical, nor syntactic) for the mapping; the hierarchical structures are already a part of syntactic derivation.

Having presented the form the linking takes in our proposal (a structure that hierarchically organizes arguments and metapredicates), let us consider its mechanism.

Only the internal substructure will be projected in HK-like structures, that is, the external argument will be excluded from the linking, and will be introduced directly in sentential syntax by a functional head. We mean by internal substructure the caused subevent, not the causing one, whenever there are two subevents related by CAUSE ${ }^{12}$. It is important to say that the external argument is always introduced in sentential syntax, in the same position (Spec of a functional projection of some kind), be it a volitional agent (argument of ACT), or any given cause. The internal argument, on the other hand, is projected in lexical syntax in different positions, depending on the verb (it may be Spec or complement of V, or Spec of P, for instance). The difference in internal argument positions is due to the different relationships that the argument might have with the metapredicates of the substructure that contains it.

Lexical-syntactic structures only see predicative relations in a semantic structure (what is a predicate, what is an argument and which argument saturates such predicate, how many arguments a certain predicate has etc). However, it is the meaning which determines whether a certain predicate is saturated or not and how many arguments it takes for its saturation. Thus, the lexical-syntactic structure sees only one type of information contained in the semantic structure and contributes with a hierarchical organization of this information. It is possible to say then that there is a "mirroring" of the semantic structure in a syntactic structure, which means that not only arguments, but also metapredicates are mapped. This is how our proposal diverges from similar proposals, in which a lexical-semantic level relates to a lexical-syntactic level, such as in Grimshaw (1990), Levin and Rappaport (1988, 1998). In these studies, only arguments are contained in the lexical-syntactic dimension ${ }^{13}$.

The semantic root is projected as the syntactic root, which has a phonologic matrix and does not bare a category label. The variables in the argument structure (semantic arguments) are projected (or reflected) as phrases of a nominal value (DPs or APs), and the metapredicates are mirrored in $\mathrm{X}^{0}$ nodes, which, depending on their semantic value, present different configurations. For example, the metapredicate BECOME, which takes an argument to get saturated, is projected as the head of a monadic structure. Let us call that nucleus V, only for the sake of naming its structure, but it is possible that this very metapredicate relates to an element of a different grammatical category in languages typologically distant from those we deal with here (Hale/Keyser 2002). A metapredicate such as WITH or IN, on the other hand, which takes two arguments to get saturated, is projected as the nucleus of a dyadic structure we call P, according to HK. A root that is ontologically STATE is also unsaturated, since a state requires an argument to get saturated. The root occupies an argument position in the lexical-syntactic structure of a monadic verb (that of a complement of V), but "demands" that

\footnotetext{
12 The structure of monoeventive verbs present problems in relation to the distinction between external and internal arguments, but these will not be discussed here. In the exemplification of the proposal in the next section, we deal only with complex (containing two subevents), causative events (related by CAUSE).

${ }^{13}$ Croft (1998) observes the same problem: the proposals in the literature hierarchize only arguments, excluding predicates. However, the way in which the author elaborates the linking from the stand point of this critic, is different from the one we present here.
} 
the verb opens a position to allocate its argument. Therefore, the argument of STATE, whenever mapped within a lexical-syntactic structure, occupies the Spec, V position, and not that of a complement of $\mathrm{R}^{14}$.

Because lexical-syntactic structures see only predicative relations in semantic structure, there will be many coincidences where distinct semantic structures are mapped onto the same syntactic structure (such as WITH and IN, which, from a predicative standpoint, are identical, because they take two arguments; from the stand point of its semantic content, however, they are different). This is expected, since semantics is richer than syntax (there are, for instance, more ontological categories than there are grammatical categories). This many-to-one mapping will be clearly exemplified in the following section.

\section{Exemplification of the proposal: verbs of change in BP}

In order to identify the verb classes that will be considered in this study, let us start from the division presented in Rappaport-Hovav and Levin (2010) for English verbs. For the authors, there is a complementary classification: either the verb is a (subtype of) result verb or a (subtype of) manner verb ${ }^{15}$. Only result verb classes in BP will be considered, particularly those which find a natural mirroring in the structures already proposed by HK. For manner verbs, something beyond HK's structures would have to be elaborated, as it was done in Mateu (2010), but they will not be considered.

The result verbs to be considered here will be called "verbs of change", which are divided into verbs of change of state, change of possession and change of location. These are nicknames, because classes are actually identified by their semantic argument structure. In fact, all three types of verbs express change of state, since relations like possession and location are stative relations. It is in this sense that the use of predicate decomposition as a language of semantic representation is justified. While the descriptions done with common language are imprecise, representations done in a specific metalanguage present, in a more objective manner, the semantic information of verbs and outline in a clear manner the similarities and differences among classes. This was argued in section 1, where predicate decomposition was presented as a more adequate language for semantic representation.

For lack of space, only synthetic verbs will be considered here, but analytical verbs also fit the mapping proposal depicted below and shall be investigated in a future study.

\subsection{Change of state verbs}

Let us begin with change of state verbs. These verbs have already been identified and studied in the literature, even in a predicate decomposition approach (such as in Levin/RappaportHovav 1995, 1998, 2005; Levin 1999; and Parsons 1990, among others). In order to identify them in BP, we use the entailment test "ficar estado" ('become state'), borrowing it from Parsons (1990). A verb such as fechar ('close'), for instance, entails ficar fechado ('become

\footnotetext{
${ }^{14}$ It is not clear from the authors' text why the argument of $\mathrm{A}$ is placed in Spec, $\mathrm{V}$, and not within a projection of A. However, as we have said, we are assuming the HK's structures as they are.

15 We refer to Rappaport-Hovav and Levin (2010)'s work for the explanation of the complementarity proposal, and to Goldberg (2010)'s work for a critique of such proposal.
} 
closed'). Plus, it is known that verbs from this class participate in the transitivity alternation called causative-inchoative, as shown below, for the same verb fechar:

$$
\begin{aligned}
& \text { a. Pedro fechou a porta. } \\
& \text { Pedro closed the door } \\
& \text { b. A porta ficou fechada. } \\
& \text { the door became closed } \\
& \text { c. A porta (se) }
\end{aligned}
$$

By means of these two tests (entailment and alternation), several change of state verbs are identified in BP; a few examples are listed below ${ }^{16}$ :

(28) amassar 'knead', amparar 'in furtherance of', apagar 'erase', arrebentar 'burst', asfixiar 'asphyxiate', colar 'paste', contundir 'bruise', curar 'cure', degelar 'defrost', desfiar 'ravel', descosturar 'unstitch', desfazer 'undo', entortar 'bend', estragar 'spoil', esvaziar 'empty', esfriar 'cool', fechar 'close', ferir 'scuff', furar 'punch', gelar 'freeze', iluminar 'illuminate', incendiar 'fire', ligar 'connect', machucar 'hurt', molhar 'wet', privilegiar 'favour', proteger 'protect', queimar 'burn', rachar 'crack', rasgar 'tear', secar 'dry', sufocar 'stifle' , sujar 'dirty', trincar 'crunch'...

Object-experiencer psychological verbs are also identified as change of state verbs:

(29) abalar 'shake', abismar 'amaze', acabrunhar 'crush', acanhar 'stunt', afligir 'afflict', agitar 'shake', agoniar 'agonize', azucrinar 'pester', baratinar 'afflict', chocar 'bump', contentar 'contenot', decepcionar 'disappoint', deleitar 'delight', deprimir 'depress', desalenta 'discourage', desanimar 'depress', desiludir 'disillusion', emocionar 'impress', encabula 'abash', encantar 'enchant', enervar 'enervate', entristecer 'sadden', enfurecer 'enrage', fascinar 'fascinate', fortalecer 'strengthen', frustrar 'dash', impacientar 'provoke', incomodar 'discomfort', pasmar 'atonish', relaxar 'relax'...

The representation that identifies change of state verbs as a class is the substructure [BECOME [Y $<$ STATE $>$ ]], in which BECOME is a one-place metapredicate (Wunderlich 2012), that takes [Y $\angle S T A T E>$ ] as its complement, which, in turn, is composed of a predicate STATE, that takes an argument, Y. STATE is also the root (Levin/Rappaport-Hovav 1998, 2005, 2010; Parsons 1990), represented in angled brackets and, in the representation of each particular verb, it assumes an idiosyncratic value (but it is always a state ontologically). For example, for the verb fechar ('close'), the relevant substructure is [BECOME [Y $<F E C H A D O>$ ]] and for abrir ('open'), it is [BECOME [Y $<A B E R T O>$ ]]. It is worth noting that, different from what Levin and Rappaport-Hovav $(2005,2010)$ seem to assume, we take STATE as a predicate - and, together with its argument Y, STATE is the argument of BECOME (BECOME predicates only one argument). We are assuming, along with Wunderlich (2012) and others, that states are predicates.

(30) a. Pedro contundiu/furou/protegeu/assustou Maria com uma tesoura. Pedro bruised/punched/protected/frightened Maria with a scissor

b. Maria foi contundida/furada/protegida/assustada por Pedro. Maria was bruised/punched/protected/frightened by Pedro

\footnotetext{
${ }^{16}$ More examples from Brazilian Portuguese can be found in Cançado, Godoy and Amaral (to appear).
} 

a. ??Pedro abalou/entristeceu/fascinou Maria com uma tesoura. Pedro shook/saddened/fascinated Maria with a scissors
b.* Maria foi abalada/entristecida/fascinada por Pedro. Maria was shaken/saddened/fascinated by Pedro

Therefore, several change of state verbs (psychological or not), can, optionally, have an agent, such as the ones in the tests in (30), but certain psych-verbs do not accept agentivity as a property of their external argument, as the ones in (31). If we use semantic predicate decomposition, this type of semantic information finds room to be represented lexically. Change of state verbs that can optionally have an agent as external argument, as proposed by Cançado (2010), are represented in (32). Change of state verbs which do not accept this possibility, referred to as "strictly causative", are represented in (33), as proposed by Cançado and Godoy (2012):

$$
\begin{aligned}
& v:[[\mathrm{X}(\mathrm{ACT})] \text { CAUSE [BECOME Y <STATE>]] } \\
& v:[[\mathrm{X}] \text { CAUSE [BECOME Y }<\text { STATE> }]]
\end{aligned}
$$

The optionally-agentive class of verbs exemplified in (28) and tested in (30) is represented in (32), in which ACT is within parenthesis ${ }^{17}$. And the strictly causative class of verbs exemplified in (29) and tested in (31) is represented in (33), in which the causing subevent is $\mathrm{X}$ alone, that is, $\mathrm{X}$ is not composed with ACT. It is worth mentioning that even when $\mathrm{X}$ denotes an individual (even when it is an animated individual), its interpretation, from the stand point of the semantic structure in which it occurs, is that of an eventuality ${ }^{18}$.

\subsection{Change of place and change of possession verbs}

Synthetic change of place verbs have already been analyzed for other languages in the literature and are more commonly referred to as location verbs (Clark/Clark 1979). It is a verbal class that contains an idea of location within its meaning, and the location gives the verb its name. These verbs are easily identify with a specific paraphrase; note that the sentence in (a) entails the sentence in (b):

(34) a. Pedro engavetou o livro.

$$
\begin{aligned}
& \text { b. O livro ficou na gaveta. } \\
& \text { the book became in the drawer }
\end{aligned}
$$

These verbs do participate in the causative-inchoative transitivity alternation:

By means of these two "tests", we have identified several change of place verbs in BP, such as:

\footnotetext{
17 Jackendoff (1990) has also postulated the possibility of lexically-marking optionality for certain predicates and arguments.

${ }^{18}$ Chierchia (2004) also proposes that the cause in verbs such as sink, in its transitive version, is an eventuality, even when the argument denotes an individual, such as in Pedro afundou o barco ('Pedro sank the boat'). The difference between the author's proposal and ours is that, for him, in every change of state verb (he does not use this nomenclature) the causing element is an eventuality. For us, only a subtype of change of state verbs requires this strictly causative interpretation. For the remaining verbs, an interpretation is possible where there is only one agent.
} 
(36) aprisionar 'imprison', arquivar 'file', aterrar 'land', embolsar 'pocket', emoldurar 'frame', empacotar 'pack', encanar 'pipe', encaixotar 'pack', encarcerar 'incarcerate', encestar 'put in basket', encovar 'bury', engaiolar 'cage', enjaular 'cage', ensacar 'bag', enterrar 'bury'...

Based on current analyses (Levin/Rappaport-Hovav 1998; Wunderlich 2012), we propose the following predicate decomposition structure to represent this verbal class' argument structure:

$$
v \text { : [[X ACT] CAUSE [BECOME Y IN <PLACE>]] }
$$

In the structure above, we show that the verbs in this class share the same predicate decomposition, differing only as to the final location of Y; this locative is the root, the verb's idiosyncratic sense. The predicate ACT is not noted within parenthesis, because these verbs are strictly agentive (only accept an agent external argument); the predicate CAUSE links the two subevents; and the predicate BECOME entails that $Y$ was not at the location denoted by the root, prior to the event (the composition of BECOME with the locative therefore implies a movement of the argument $Y$ in the course of the eventuality).

Synthetic verbs of change of possession in BP include what is known in the literature as locatum verbs (Clark/Clark 1979):

$$
\begin{array}{lll}
\text { Pedro selou o cavalo. } \\
\text { Pedro saddled he } & \text { horse } \\
\text { Pedro amanteigou } & \text { o pão. } \\
\text { Pedro buttered } & \text { the bread }
\end{array}
$$

Change of possession verbs contain an object that changes possessions as part of their meaning, and this specific object names each verb, as shown with the paraphrases below. It is worth mentioning that we understand "possession" in a broad manner, as do several authors in the literature, such as HK. Both types exemplified above in (38) and in (39) have the following entailment relation with the expression $Y$ becomes with $R$ :

$$
\begin{array}{llll}
\mathrm{O} \text { cavalo } & \text { ficou } & \text { com (uma) sela. } \\
\text { the horse } & \text { became } & \text { with } & \text { (a) saddle } \\
\mathrm{O} \text { pão } & \text { ficou } & \text { com manteiga. } \\
\text { the bread } & \text { became } & \text { with butter }
\end{array}
$$

As with location verbs, neither type of change of possession verbs accepts the causativeinchoative transitivity alternation:

$$
\begin{array}{llll}
* O & \text { cavalo } & \text { (se) } & \multicolumn{1}{c}{\text { selou. }} \\
\text { the } & \text { horse } & \text { (clitic se) } & \text { saddled } \\
\text { *O pão } & \text { (se) } & \text { amanteigou. } \\
\text { The bread } & \text { (clític se) } & \text { buttered }
\end{array}
$$

Using these two "tests", we can identify several change of possession verbs in BP, such as:

(44) acorrentar 'enchain', aferrolhar 'bolt', adubar 'fertilize', agasalhar 'shelter', apimentar 'spice with peper', cimentar 'cement', concretar 'put concret', coroar 'crown', temperar 'temper'... (locatum)

As far as the difference between change of possession and change of place verbs is concerned, although both classes present similar behavior in relation to the causative-inchoative alternation, each class differ in relation to reflexivization, as we have seen in section 1 . We 
therefore argue that such difference is due to a lexical-semantic particularity: while one class denotes an event in which an individual/object changes place, the other denotes an event in which an individual/object changes possession. This difference is easily captured in a semantic predicate decomposition. Thus, based on Levin and Rappaport-Hovav (1998) and Wunderlich (2012), we propose the following semantic representation for the argument structure of change of possession verbs:

$$
\text { v: [[X ACT] CAUSE [BECOME Y WITH <THING>]] }
$$

The structure above represents what the verbs from this class share - a predicate structure in which ACT is mandatory (only an agent can be the external argument), there are two subevents linked by CAUSE and there is a predicate BECOME, that, composed with the "possessive" argument introduced by the predicate WITH, implicates, as a change, that Y did not have the entity indicated by the root prior to the eventuality. The element that differentiates one verb from the other within this class is the root, which contains the idiosyncratic part of the verbal meaning. By means of the proposed structures, we can more formally represent what the classes of change of location and change of possession share, and in which aspect of their meaning they differ. We have argued that the semantic content of the abstract preposition of location and locatum verbs must be represented in argument structure, because syntax is sensitive to it. This distinction was done using the metapredicates IN and WITH, which represent the only difference between the two classes.

In this section, we have presented the verbs of change in BP and proposed representations for their semantic argument structures, in which we could allocate semantic information that is grammatically relevant (optional agentivity and the semantic content of abstract prepositions), which do not fit in syntactic argument structures. Let us now show how the mapping of these structures onto sentential syntax occurs, making use of HK's structures.

\subsection{Linking}

Let us take a look at the representations of the three verbal classes of change of state, highlighting in bold the part which is relevant to linking (internal substructure, as explained in section 2):

$$
\begin{aligned}
& \text { v: [[X ACT] CAUSE [BECOME Y <STATE }>]] \\
& v:[[\mathrm{X} \text { ACT] CAUSE [BECOME Y IN }<P L A C E>]] \\
& v:[[\mathrm{X} \text { ACT] CAUSE [BECOME Y WITH }<\text { THING }>]]
\end{aligned}
$$

Let us begin with change of state verbs. Metapredicates and semantic arguments correspond to phrases or elements of some grammatical category ${ }^{19}$, which will fill the nodes on lexicalsyntactic configurations (as it was explained in section 2). This correspondence happens in the following manner:

(49) [BECOME [Y $<$ STATE $>$ ]]]

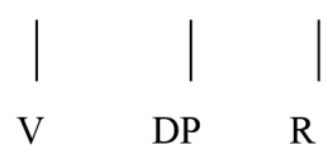

\footnotetext{
${ }^{19}$ It is worth repeating that we understand "grammatical category" as information on solely predicative (is it an argument or a predicate; how many arguments does it take in order to be saturated).
} 
$\mathrm{V}$ is a nucleus that takes $\mathrm{R}$ as argument, which, in turn, due to its semantics, is a predicate which takes DP as argument. Assuming HK structures as they are, these elements only fit the composite dyadic structure, in (24), repeated bellow, where DP, which is an argument of R, actually occupies a relational position of $\mathrm{V}$, as reported in section 2 :

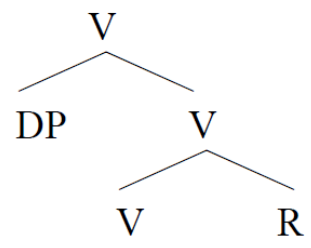

Let us now postulate how metapredicates and semantic arguments correspond to elements and phrases of some syntactic category, for change of place and change of possession verbs:

$(51)$

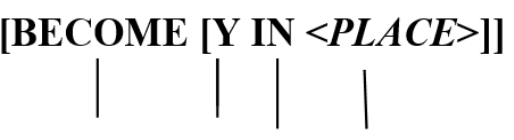

V DP P R
(53) $[$ B

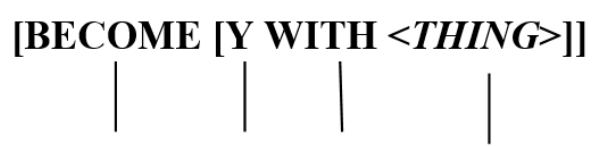

$\mathrm{V} \quad \mathrm{DP} \quad \mathrm{P} \quad \mathrm{R}$

If linking structures only see predicative relations in semantic structures, then IN and WITH are identical from a purely syntactic point of view (both take two arguments to get saturated). $\mathrm{V}$ takes $\mathrm{P}$ as complement, which in turn needs two places for its arguments, DP and R (here, $\mathrm{R}$ is an argument, not a predicate, as in change of state verbs). In a tree structure, these elements are hierarchized in the following manner (the HK structure here is the same for both classes):

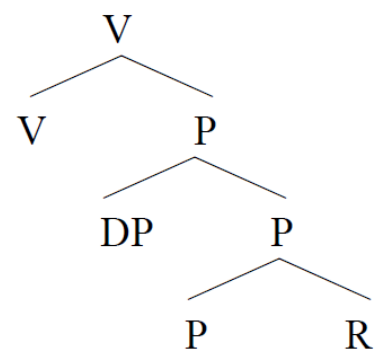

Taking BP verbs of change as examples for our proposal, we showed how to represent them in a semantic metalanguage that is able to represent meanings which are grammatically relevant. The correspondence between these semantic structures and HK structures, which serve as the mapping between lexicon and syntax, occurs in a somewhat natural manner, because a) semantic components find a parallel in syntactic categories (containing only the predicative information of the elements), and b) these categories organize themselves syntactically according to independent grammatical principles, such as hierarchy and binarity. This linking is not an artificial theoretical object or a mere generalization, but it is motivated by grammatical principles. Lexical-syntactic structure can further predict that the transitivity alternation called "causative-inchoative" is possible with change of state verbs and impossible with change of location and change of possession verbs. If there is a DP in Spec, V, then it can either raise to subject position, in the absence of an external argument (inchoativeintransitive form), or occupy the object position in the presence of an external argument 
(causative-transitive form). For change of possession and change of location verbs, there is no Spec, $\mathrm{V}$, therefore, there is no argument that can be alternated. This is in consonance with the semantic argument structure that we have proposed for these verbs, in which ACT is mandatory. In other words, semantically, agentivity is mandatory; syntactically, if there is not an internal argument that can be alternated, the introduction of an external argument in syntactic derivation becomes mandatory. With this example, it is possible to observe how the two structures, lexical-semantic and lexical-syntactic, relate to each other in a natural manner.

The lexical-syntactic structure we used for linking, however, cannot explain differences the classes present in relation to passivization and reflexivization. That follows, since if both operations are sensitive to semantic information about the external argument (passivization requires agentivity in the external argument and reflexivization sees its denotative value), it is expected that lexical syntax, which does not comprise the external argument, will have nothing to say about them. Once again, we confirm the need for a lexical-semantic level, where grammatically relevant semantic information can be allocated.

It is worth emphasizing that what we have used to exemplify our theoretical proposal is a cutout. We have only looked at synthetic verbs of change, with semantic structures of predicate decomposition that fit well in HK's lexical-syntactic structures. Other verbal classes from BP would demand analysis. Taking this initial sampling as a starting point, we propose a research program in which other classes can be analyzed in the approach weaved here (a semantic argument structure represented by predicate decomposition and mapped onto syntax by means of HK's lexical-syntactic structures).

In order to close this section, let us evaluate in which sense a linking as the one we are proposing here seems to work better than some other type of mapping. It is important to highlight that the particularity of our linking is the fact that it maps predicates as well, not only arguments, in a lexical-syntactic hierarchic structure. If the linking contained only the ordering of the arguments from the semantic predicate structure and if we understand thematic roles as positions within this structure (Jackendof 1990), then, thinking only of verbs of change (to simplify), we would have a hierarchy of functions/roles as follows:

\section{Argument of ACT > Argument of BECOME > Argument of STATE, IN or WITH $>$ Argument of IN or WITH}

When we observe our data more carefully, several problems would arise if we adopted the hierarchy above. First, while a variable X may be an argument of ACT, ACT is sometimes optional (such as in agentive-causative change of state verbs) or inexistent (such as in strictly causative verbs). Therefore, we should exchange "argument of ACT" for "argument of ACT or CAUSE". However, we saw that CAUSE links two subevents; which of the two would be the "argument of CAUSE"? The second problem is that BECOME does not take a variable as an argument, but a stative substructure ([Y $<$ STATE $>$ ], [Y IN $<P L A C E>$ ] or [Y WITH $<$ THING $>$ ]), thus, even though the "argument of BECOME" does exist in the semantic structure, it does not refer to a syntactic DP. Third, if WITH and IN are bi-relational, which of their arguments is mapped?

The problem of hierarchies such as the one above is precisely pointed out by Croft (1998: 22): "the fundamental problem (...) is that once thematic roles are derived from the semantic structure of events, the rest of event structure semantics is so to speak thrown away". We 
agree with the author that "other aspects of event structure are crucial for argument linking" (ibd.). In our proposal, these aspects are the metapredicates, which must be mapped along with their arguments.

A second type of mapping that could be proposed is similar to the one proposed by Jackendoff (1990). The author postulates an indexing of variables from semantic structure in the verb's subcategorized noun phrases. All of this would be enclosed in the lexical entry for each particular verb. For example, in the lexical entry for each location or locatum verb, there would be a specification of which argument occupies subject position in syntax. A linking of arguments that must be specified for each particular verb is, for obvious reasons, less preferable than a mapping which manages to serve for at least a group of verbs.

Both possibilities of linking - that of a hierarchy of functions and the linking which is individual for each verb - seem to be examples of what Pylkkanen (2008) calls "mere generalizations", in opposition to a linking which is more motivated by grammatical principles.

\section{$5 \quad$ Final considerations}

This text's main idea is that of an explicit unification of semantic predicate decomposition with syntactic predicate decomposition representations. In the proposal developed, semantic predicate decomposition representations assume the role of argument structure, the part of the lexical information which is relevant to grammar. Syntactic predicate decomposition representations (which are in essence Hale/Keyser's 2002 structures), on the other hand, assume the role of linking structures, which map lexical-semantic structures onto syntax itself. These lexical-syntactic structures can be assumed to exist in syntax, in what is called the "lexical phase" of the derivation (Ramchand 2008). We showed evidence that an argument structure containing semantic information is necessary. Also, we argued for a representation of semantic argument structure in terms of predicate decomposition. Since a semantic argument structure is necessary, a mapping principle for that is also needed, like in any other semantic theory of lexical information. We argued for syntactic decompositional structures to assume the role of linking mechanisms. The point in which our proposal is different is the fact that we propose mapping not only arguments, but also predicates in our linking. We have therefore a mirroring of semantic decomposition structures into lexical-syntactic linking structures. There is a correspondence between semantic and lexical categories and the lexicalsyntactic level sees only predicative information in semantic structures, contributing with a hierarchy of that information. Therefore, we intend our linking to be natural, meaning that it is not a stipulated mechanism, but something which is independently motivated by already existent grammatical principles. Both for the evidence for the need of semantic information in argument structure and for the exemplification of the theoretical proposal, we used Brazilian Portuguese data. More specifically, we mention passivization and reflexivization properties and describe the great class of verbs of change in BP. Obviously, we did not describe all verbal classes in BP, so we aim at inaugurating a program for describing and explaining other verbal classes within the framework we propose, in future work. 


\section{References}

Baker, Mark (1988): Incorporation: A Theory of Grammatical Function Changing. Chicago/London: University of Chicago Press.

Belleti, Adriana/Rizzi, Luigi (1988): "Psych Verbs and Theta-Theory". Natural Language and Linguistic Theory 6: 291-352.

Borer, Hagit (2005): The Normal Course of Events. Oxford: Oxford University Press.

Cançado, Márcia (2010): "Verbal alternations in Brazilian Portuguese: a lexical semantic approach". Studies in Hispanic and Lusophone Linguistics 3/1: 77-111.

Cançado, Márcia/Amaral, Luana (2010): "Representação lexical de verbos incoativos e causativos do PB" ('Lexical representation of causative and inchoative verbos of BP'). Revista da ABRALIN 9/2: 123-147.

Cançado, Márcia/Franchi, Carlos (1999): "Exceptional Binding with Psych-Verbs?" Linguistic Inquiry 30/1: 133-143.

Cançado, Márcia/Godoy, Luisa (2012): "Representação Lexical de Classes Verbais do Português Brasileiro" ('Lexical representations of verb classes of Brazilian Portuguese'). ALFA 56/1: 109-135.

Cançado, Márcia/Godoy, Luisa/Amaral, Luana (to appear): Catálogo de Verbos do Português Brasileiro. Belo Horizonte: Editora UFMG.

Chafe, Wallace (1970): Meaning and the Structure of Language. Chicago: Chicago University Press.

Chierchia, Genaro (2004): "A semantics for unaccusatives and its syntactic consequences". In: Alexiadou, Artemis/Anagnostopoulou, Elena/Everaert, Martin. (eds.) (2004): The Unaccusativity Puzzle. Oxford : Oxford University Press: 22-59.

Clark, Eve/Clark, Herbert (1979): "When nouns surface as verbs". Language 55: 767-811.

Croft, William (1998): "Event Structure in Argument Linking". In: Butt, Miriam/Geuder, Wilhelm (eds.) (1998): The projection of arguments: lexical and compositional factor. Chicago: CSLI Publications: 21-63.

Doron, Edit/Rappaport-Hovav, Malka (2009): "A Unified Approach to Reflexivization in Semitic and Romance". In: Bendjaballah Selma et al. (eds.) (2009): Brill's Annual of Afroasiatic Languages and Linguistics. Leiden: Brill: 75-105.

Dowty, David (1979): Word Meaning and Montague Grammar. Dordrecht: Reidel.

Dowty, David (1991): "Thematic Proto-Roles and Argument Selection". Language 67: 547619.

Godoy, Luisa (2012): A reflexivização em PB e a decomposição semântica de predicados. ('Reflexivization in BP and the semantic decomposition of predicates'). Unpublished doctoral dissertation. UFMG, Brazil.

Fillmore, Charles (1968): "The Case for Case". In: Bach, Emmon/Harms, Robert (eds) (1968): Universals in Linguistic Theory. New York/Holt, Rinnehart and Winston: 1-88.

Fillmore, Charles (1971): "Some Problems for Case Grammar". Monograph Series on Language and Linguistics 24: 35-56. Washington: Georgetown University Press.

Fodor, Jerry (1970): "Three reasons for not deriving 'kill' from 'cause to die'". Linguistic Inquiry 1: 429-438.

Goldberg, Adele (1995): Constructions: A Construction Grammar Approach to Argument Structure. Chicago: University of Chicago Press. 
Márcia Cançado and Luisa Godoy: Predicate Decomposition, and Linking Syntax and Semantics: 65 A Brazilian Portuguese Analysis

Goldberg, Adele (2010): "Verbs, Constructions and Semantic Frames". In: Malka Rappaport Hovav/Doron, Edit/Sichel, Ivy (eds.) (2010): Syntax, Lexical Semantics, and Event Structure. Oxford, Oxford University Press: 39-58.

Grimshaw, Jane (1982): "On the Lexical Representation of Romance Reflexive Clitics". In: Bresnan, Joan (ed.) (1982): Mental Representations of Grammatical Relations. Cambridge, MIT Press: $87-148$.

Grimshaw, Jane (1990): Argument Structure. Cambridge: MIT Press.

Grimshaw, Jane (2005): Words and Structure. Stanford: CSLI Publications.

Gruber, Jeffrey (1965): Studies in Lexical Relations. Doctoral Dissertation. MIT.

Hale, Kenneth/Keyser, Samuel (1993): "On Argument Structure and the Lexical Expression of Syntactic Relations". In Hale, Kenneth/Keyser, Samuel (eds.) (1993): The View from Building 20. Cambridge, MIT Press: 53-109.

Hale, Kenneth/Keyser, Samuel (2002): Prolegomenon to a Theory of Argument Structure. Cambridge: MIT Press.

Harley, Heidi (2007): "The bipartite structure of verbs cross-linguistically". In: CristófaroSilva, Thais/Mello, Heliana (eds) (2007): Conferências do V Congresso Internacional da Associação Brasileira de Linguística. Belo Horizonte, UFMG: 45-84.

Jackendoff, Ray (1972): Semantic Interpretations in Generative Grammar. Cambridge: MIT Press.

Jackendoff, Ray (1990): Semantic Structures. Cambridge: MIT Press.

Kaine, Richard (1975): French Syntax: The Transformational Cycle. Cambridge: MIT Press.

Kaufman, Ingrid (2007): "Middle voice". Lingua 11: 1677-1714.

Kemmer, Suzanne (1993): The Middle Voice. Amsterdam: John Benjamins.

Klaiman, M. H. (1991): Grammatical voice. Cambridge: Cambridge University Press.

Kratzer, Angelika (1996): "Severing the External Argument from its Verb". In: Rooryck, Joan/Zaaring, Lauri (eds.) (1996): Phrase Structure and the Lexicon. Dordrecht, Kluver: $109-423$.

Landau, Idan (2010): The Locative Syntax of Experiencers. Cambridge: MIT Press.

Lakoff, Georg (1970): Irregularity in Syntax. New York: Holt, Rinehart and Winston.

Levin, Beth (1993): English verb classes and alternations. Chicago: The University of Chicago Press.

Levin, Beth (1999): "Objecthood: an event structure perspective". CLS 35, Part 1, Main Session, Chicago Linguistic Society, Chicago, IL: 223-247.

Levin, Beth (2009): "Further Explorations of the Landscape of Causation: Comments on the Paper by Alexiadou and Anagnostopoulou". Proceedings of the Workshop on Greek Syntax and Semantics, MIT Working Papers in Linguistics 49. Cambridge, MIT Press: 239-266.

Levin, Beth/Rappaport-Hovav, Malka (1995): Unaccusativity: at the syntax-lexical semantics interface. Cambridge: MIT Press.

Levin, Beth/Rappaport-Hovav, Malka (1998): "Building verb meanings". In: Butt, Miriam/Geuder, Wilhelm (eds.) (1998): The projection of arguments: lexical and compositional factors. Chicago, CSLI Publications: 21-63.

Levin, Beth/Rappaport-Hovav, Malka (2005): Argument Realization. NY: Cambridge University Press. 
McCawley, James D. (1968): "The Role of Semantics in a Grammar". In: Bach, Emmon/Harms, Robert (eds.) (1968): Universals in Linguistic Theory. New York, Holt, Rinehart and Winston: $125-170$.

Maldonado, Ricardo (1999): A Media Voz. Mexico: Universidade Nacional Autónoma de México.

Marantz, Alec (1984): On the Nature of Grammatical Relations. Cambridge: MIT Press.

Marantz, Alec (1997): "No escape from syntax: Don't try morphological analysis in the privacy of your own lexicon". Penn Linguistics Colloquium 21: 201-225.

Mateu, Jaume (2010): "On the L-Syntax of Manner and Causation". In: Duguine, Maia/Huidobro, Susana/Madariaga, Nerea (eds.) (2010): Argument structure and syntactic relations. Amsterdam: John Benjamins: 89-112.

Morgan, Jerry (1969): "On arguing about semantics". Papers in Linguistics 1: 49-70.

Parsons, Terence (1990): Events in the Semantics of English: a study in subatomics semantics. Cambridge: MIT Press. (=Currents Studies in Linguistic Series 19).

Pesetsky, David (1995): Zero Syntax. Cambridge: MIT Press.

Pinker, Steven (1989): Learnability and Cognition. Cambridge: MIT Press.

Pylkkanen, Liina (2008): Introducing Arguments. Cambridge: MIT Press. (= Linguistic Inquiry Monograph 49).

Ramchand, Gillian (2008): Verb Meaning and the Lexicon: a First Phase Syntax. Cambridge: Cambridge University Press.

Rappaport, Malka/Levin, Beth (1988): "What to do with theta-roles". In: Wilkins, Wendy (ed.) (1988): Syntax and Semantics: Thematic Relations 21. San Diego, Academic Press: 7-36.

Rappaport-Hovav, Malka/Levin, Beth (2010): "Reflections on Manner/Result Complementarity". In: Malka Rappaport Hovav/Doron, Edit/Sichel, Ivy (eds.) (2010): Syntax, Lexical Semantics, and Event Structure. Oxford, Oxford University Press: 21-38.

Reinhart, Tanya/Siloni, Tal (2005): "The lexicon-syntax parameter: reflexivization and other arity operations". Linguistic Inquiry 63: 389-436.

Ross, John Robert (1969): "Guess Who?". In: Binnick, Robert et al. (eds.) (1969): Papers from the Fifth Regional Meeting of the Chicago Linguistic Society. Chicago, University of Chicago Press: 252-286.

Van Valin, Robert Jr./LaPolla, Randy (1997): Syntax: Structure, Meaning and Function. Cambridge: Cambridge University Press.

Van Valin, Robert Jr. (2005): Exploring the Syntax-Semantics Interface. Cambridge: Cambridge University Press.

Von Stechow, Arnim (1995): "Lexical Decomposition in Syntax". In: Egli, Urs et al (eds.) (1995): Lexical knowledge in the organization of language. Amsterdam, John Benjamins: 81-118.

Wunderlich, Dieter (1997): "Cause and the structure of verbs". Linguistic Inquiry 28/1: $27-$ 68.

Wunderlich, Dieter (2012): "Lexical decomposition". In: Werning, Markus et al. (eds.) (2012): The Oxford Handbook of Compositionality. Oxford University Press: 31-65. 